\title{
Pervaporation of Ethanol/Water Mixtures using Novel Hydrophobic Membranes Based on Concentrated Emulsion Polymerization
}

\author{
Shengpeng SHI, Zhongjie Du, Chen ZHANG, and Hangquan $\mathrm{LI}^{\dagger}$ \\ The Key Laboratory of Beijing City on Preparation and Processing of Novel Polymer Materials, \\ Beijing University of Chemical Technology, Beijing 100029, China
}

(Received May 2, 2005; Accepted August 19, 2005; Published December 15, 2005)

\begin{abstract}
A pervaporation membrane was prepared via the concentrated emulsion polymerization method. The concentrated emulsion formed was pre-polymerized, after which a mixture of another hydrophobic monomer, a crosslinker and an initiator were added with stirring to the system. The gel formed was located between two glass plates and subjected to polymerization. The membrane copied the structure of its precursor concentrated emulsion and composed of closely packed latexes that squeezed each other. The micro-channel among the latexes provided additional pathways for the permeates. The morphologies of the concentrated emulsion and membrane were examined via optical and electron microscopies. The pervaporation performance of the membrane in the extraction of ethanol from ethanol/water mixtures was investigated. In certain ranges of composition, the flux and selectivity simultaneously increased.
\end{abstract}

[DOI 10.1295/polymj.37.925]

KEY WORDS Pervaporation Membrane / Ethanol / Concentrated Emulsion /

The emphasis in this paper is on a new method to prepare pervaporation membranes. The prepared membranes will be used to pervaporate ethanol from ethanol/water mixtures. While the pervaporation of water from ethanol/water mixtures was investigated in a large numbers of papers, ${ }^{1-6}$ the pervaporation of ethanol from such mixtures was examined in much fewer papers and is more difficult to achieve.

Between ethanol and water, ethanol is more hydrophobic; for this reason, hydrophobic materials were naturally selected to pervaporate ethanol from ethanol/water mixtures. ${ }^{7-10}$ Most of the membranes were based on homopolymers or copolymers of siloxanes. However, polydimethylsiloxane membranes prepared using conventional methods, such as solvent casting and hot pressing, were dense membranes. Their total permeation rates were between 7 and $160 \mathrm{~g} /\left(\mathrm{m}^{2} \cdot \mathrm{h}\right)$, with selectivity between 2.4 and $6.7\left(30-37^{\circ} \mathrm{C}, 10\right.$ wt $\%$ ethanol in water), and an increase in selectivity was often associated with a decrease in the flux. ${ }^{11,12}$ Such performances are not satisfactory in applications.

It was noticed that the polymeric membrane prepared via traditional methods are all dense ones, ${ }^{13-16}$ in which the gap among the chains provides the pathway of the permeates. However, the average interchain distance among the amorphous flexible chains is $0.4-0.5 \mathrm{~nm}^{17}$ and the van der Waals radius of ethanol molecules is $0.52 \mathrm{~nm}$. For this reason, the interchain gap is not big enough for ethanol molecules to diffuse. In other words, the separation selectivity is not only controlled by the polarity, but also by the size of the molecule. For the purpose of preferably separation of ethanol from water, additional larger pathway for permeates should be provided. Among various preparation methods developed, concentrated emulsion polymerization constitutes the first choice.

A series of hydrophilic/hydrophobic composite membranes was prepared via the concentrated emulsion polymerization method. ${ }^{18,19}$ In a concentrated emulsion, the volume fraction of the dispersed phase is larger than 0.74 (which represents the volume fraction of the most compact arrangement of spheres of equal radii) and can be as large as $0.99 .{ }^{20}$ At large volume fractions, the dispersed phase is composed of polyhedral cells separated by films of the continuous phase. For the preparation of the hydrophilic/ hydrophobic membranes, the polymerizations were carried out in both phases. The dispersed phase was selected to yield a hydrophobic or hydrophilic polymer which is compatible with the components selected for separation and incompatible with the other components, while the continuous phase was selected to yield a hydrophilic or hydrophobic polymer which is incompatible with all of the components of the mixture, and thus it can ensure the integrity of the membrane. The hydrophobic materials employed included polystyrene, polydimethylsiloxane, styrenebutadiene-styrene triblock copolymer (SBS), styrene/ ethylene-butylene/styrene (SEBS), and polybutyl acrylate, the hydrophilic ones included poly(acrylic acid), poly(sodium acrylate) and their crosslinker,

${ }^{\dagger}$ To whom correspondence should be addressed (Tel: +86-010-64445339, Fax: +86-010-64428804, E-mail: hli45@yahoo.com.cn). 
$N, N^{\prime}$-methylene-bisacrylamide.

The hydrophilic/hydrophobic composite are superior to the dense ones because diffusion pathways exist among the cells of the emulsion, in addition to those through the cells. When used for extracting ethanol from water, the hydrophilic/hydrophobic composite had the shortcoming that the hydrophilic continuous phase was harmful to the selectivity.

In this paper, a membrane was prepared via the concentrated emulsion polymerization. However, the polymerization was carried out in the dispersed phase only. As a result, the hydrophobic particles were separated no longer by hydrophilic films but micro-channels, which provided pathways for the permeates in addition to those in the dense particles. The separation performance resulted from such a structure was examined.

\section{EXPERIMENTAL}

\section{Materials}

Octamethyl cyclotetrasiloxane $\left(\mathrm{D}_{4}\right)$, vinyl heptamethyl cyclotetrasiloxane $\left(\mathrm{ViD}_{4}\right)$, and potassium hydroxide $(\mathrm{KOH})$ were purchased from Beijing Huaer Co. Ltd., China; Styrene and Cetyl trimethyl ammonium bromide (CTAB) were supplied by Tianjin No. 6 Chemical Reagent Co., China; divinyl benzene (DVB) and 2,2'-azobisisobutyronitrile (AIBN) were provided by Shanghai Chemical Reagent Corp., China. $\mathrm{D}_{4}$, $\mathrm{ViD}_{4}$ and styrene (St) were purified by distillation under reduced pressure before use and the other chemicals were used as received. Water was distilled and deionized.

\section{Preparation of the Membrane}

Into an aqueous solution of CTAB (the surfactant, $0.04 \mathrm{~g} / \mathrm{g}$ water) and $\mathrm{KOH}$ (catalyst, $0.04 \mathrm{~g} / \mathrm{g}$ water), a mixture of $\mathrm{D}_{4}$ and $\mathrm{ViD}_{4}$ (denoted further as $\mathrm{D}_{4} \mathrm{~s}$ ) was introduced dropwise as dispersed phase until their volume fraction became 0.75 . The concentrated emulsion was pre-polymerized at $80^{\circ} \mathrm{C}$ for $3 \mathrm{~h}$. Subsequently, the system was cooled to room temperature and a mixture of St, DVB and AIBN was added dropwise with stirring. St, DVB and the initiator AIBN were dissolved into the pre-polymerized cells (droplets). The addition lasted about $10 \mathrm{~min}$ and the stirring was maintained for 15 more min in order to ensure the mixing of the components. The system was subsequently retrieved, sandwiched between two flat glass plates, and introduced into an oven protected by a $\mathrm{N}_{2}$ atmosphere to carry out a free radical copolymerization at $50^{\circ} \mathrm{C}$ for $24 \mathrm{~h}$.

The recipes used in the preparation are listed in Table I.
Table I. Recipe of the monomers for the preparation of the membranes

\begin{tabular}{ccccc}
\hline \multirow{2}{*}{ No. } & \multicolumn{4}{c}{ Composition of dispersed phase (volume parts) } \\
\cline { 2 - 5 } & $\mathrm{D}_{4}$ & Vi D $_{4}$ & Styrene & DVB \\
\hline 1 & 38 & 12 & 10 & 2 \\
2 & 38 & 12 & 14 & 2 \\
3 & 38 & 12 & 18 & 2 \\
4 & 38 & 12 & 23 & 2 \\
5 & 38 & 12 & 28 & 2 \\
\hline
\end{tabular}

\section{Morphology Examination}

The morphology of the concentrated emulsion during the polymerization was examined with an optical microscope (Nikon PFX, Japan). The fractured surface of the membrane was examined by scanning electron microscope (Cambridge S-250MKIII, UK). A thin film of gold was applied on the surface before examination.

\section{Pervaporation}

A schematic representation of the pervaporation apparatus is presented in Figure 1. The membrane with the thickness of about $0.75 \mathrm{~mm}$ located in the permeation cell possessed an effective surface area of $18 \mathrm{~cm}^{2}$. The capacity of the feed reservoir was $5 \mathrm{~L}$, the temperature of the feed was kept at $16^{\circ} \mathrm{C}$. A constant downstream pressure of $5 \pm 1 \mathrm{mmHg}$ was maintained with a vacuum pump.

After $2 \mathrm{~h}$ of running the apparatus at the operating temperature without condensation, the permeated vapor was allowed to condense in a cold trap with liquid nitrogen for $10 \mathrm{~h}$. The composition of the product was analyzed with a refractometer.

The pervaporation flux $J$ (in $\mathrm{g} /\left(\mathrm{m}^{2} \cdot \mathrm{h}\right)$ ) and the separation factor $\alpha$ were calculated using the expressions: $J=\frac{Q}{A \cdot t}$ and $\alpha=\frac{Y_{\mathrm{E}} / Y_{\mathrm{W}}}{X_{\mathrm{E}} / X_{\mathrm{W}}}$, where $Q=$ weight $(\mathrm{g})$ of permeate, $t=$ permeation time (h), $A=$ membrane area $\left(\mathrm{m}^{2}\right) ; X_{\mathrm{E}}$ and $X_{\mathrm{W}}$ represent the weight fractions of ethanol and water of the feed mixture, and $Y_{\mathrm{E}}$ and $Y_{\mathrm{W}}$ represent the weight fractions of ethanol and water of the permeate, respectively.

\section{RESULTS AND DISCUSSION}

In the concentrated emulsion polymerization, each cell (droplet) polymerizes almost individually as a kind of micro-reactor. As a result, the polymerized latexes retain the shape and size of their precursor droplets. However, because in a concentrated emulsion, the droplets are tightly compacted, diffusion of species among them can occur. When the chains of the polymer are sufficiently flexible, segments can diffuse through the boundaries of the cells to other cells resulting in aggregation. The chains of polydimethyl- 


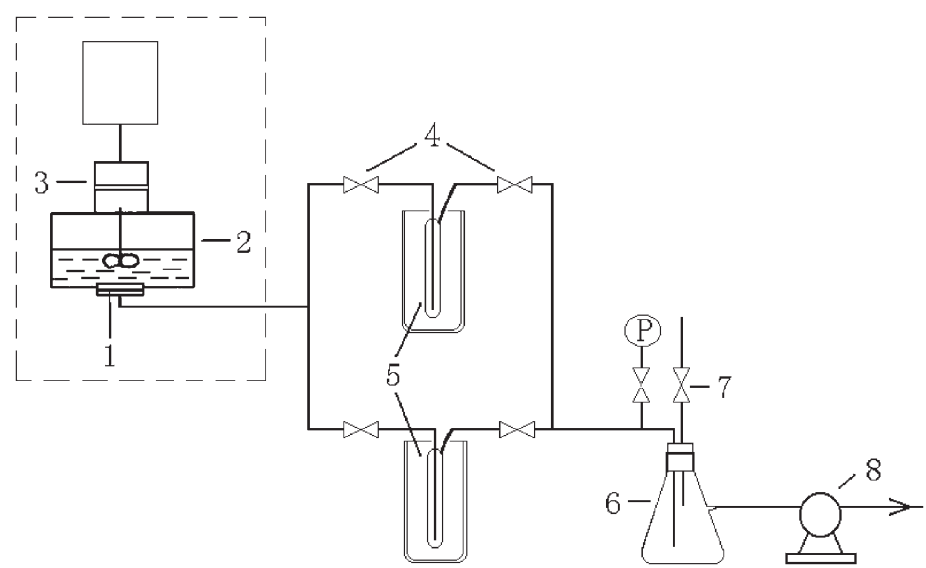

Figure 1. Schematic diagram of the pervaporation apparatus: (1) membrane; (2) feed reservoir; (3) mechanical stirrer; (4) switch valve; (5) collection trap; (6) safety trap; (7) switch valve; (8) vacuum pump.<smiles>C=C[Si](C)(C)O[Si](C)(C=C)O[Si](C)(C)C</smiles>

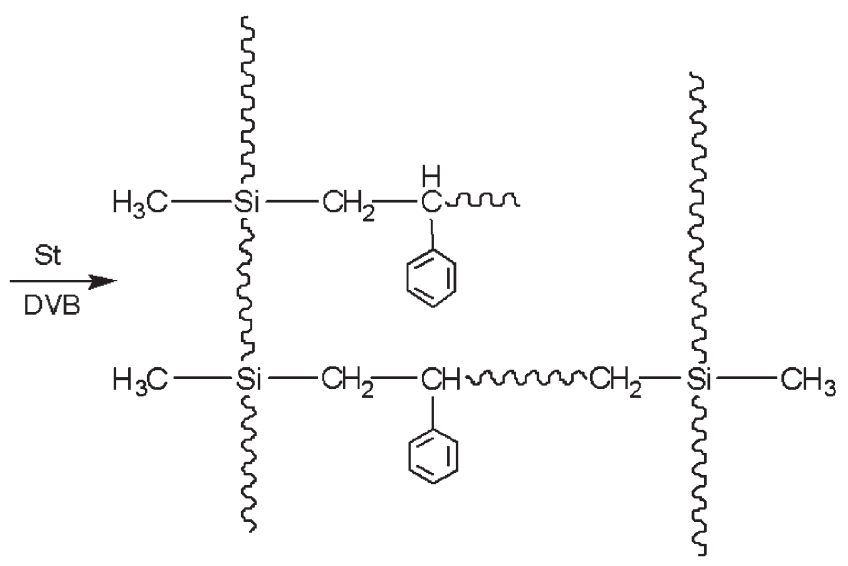

Figure 2. Schematic diagram of the reaction and the obtained chemical structure.

siloxane are extremely flexible. For this reason, the latexes can easily coagulate.

To inhibit this tendency, various amount of styrene and its crosslinker, DVB (denoted hard units in what follows) were introduced to copolymerize with polydimethylsiloxane segments through the double bonds of $\mathrm{ViD}_{4}$ and to crosslink the polymers in the cells and for inter-cell crosslinking (see Figure 2). The crosslinking stabilizes the interface of the cells and the membrane itself.

Figure 3 presents the morphology of the concentrated emulsion during the polymerization after the hard units were introduced. One can see that the individuality of the latexes was well maintained. In the samples devoid of hard units, the latexes coagulated to form a uniform, dense material.

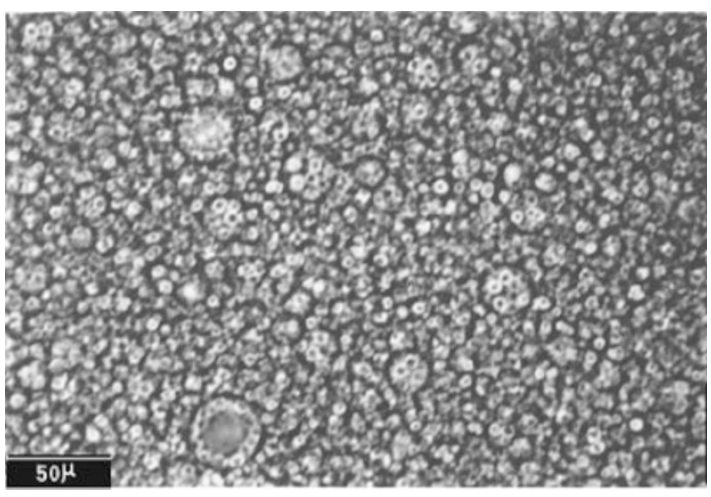

(a)

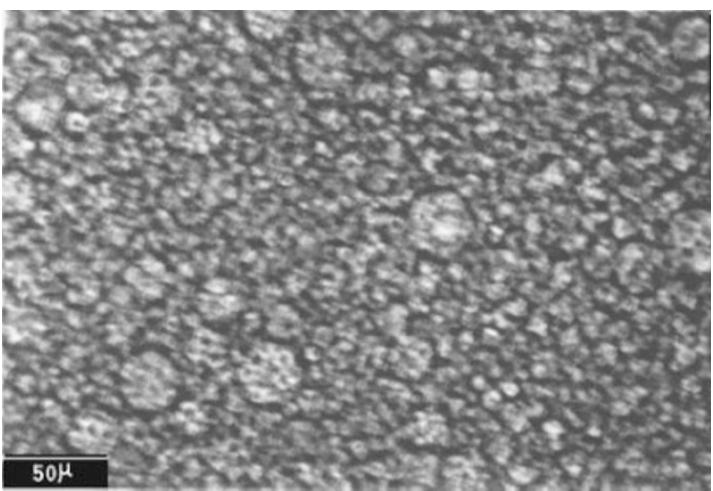

(b)

Figure 3. Morphology of the concentrated emulsion during polymerization (a) $1 \mathrm{~h}$; (b) $2 \mathrm{~h}$, both after the addition of hard units (18 volume parts); the sum of the volume parts of styrene and DVB, see Table I.

Figure 4 presents the morphologies of the membranes with various contents of hard units. Comparing Figure 4 with Figure 3, one can notice that the morphology of the precursor cells was essentially retained by the membrane and that the degree of individuality of the latexes was dependent upon the amount of hard units introduced. When the amount was low, the latexes coagulated to some extent. As the amount of hard 


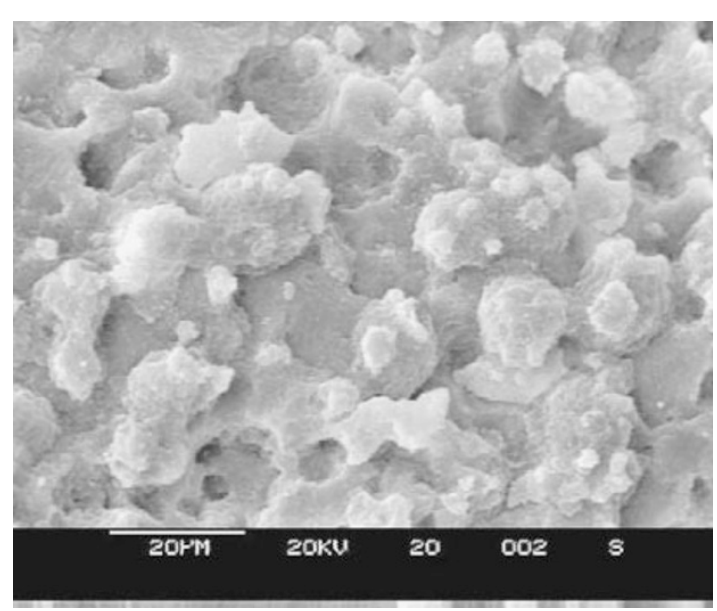

(a)

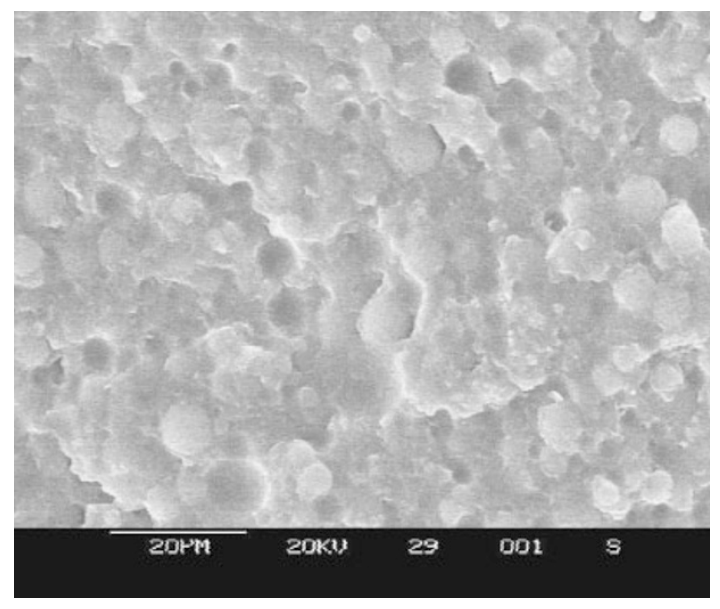

(b)

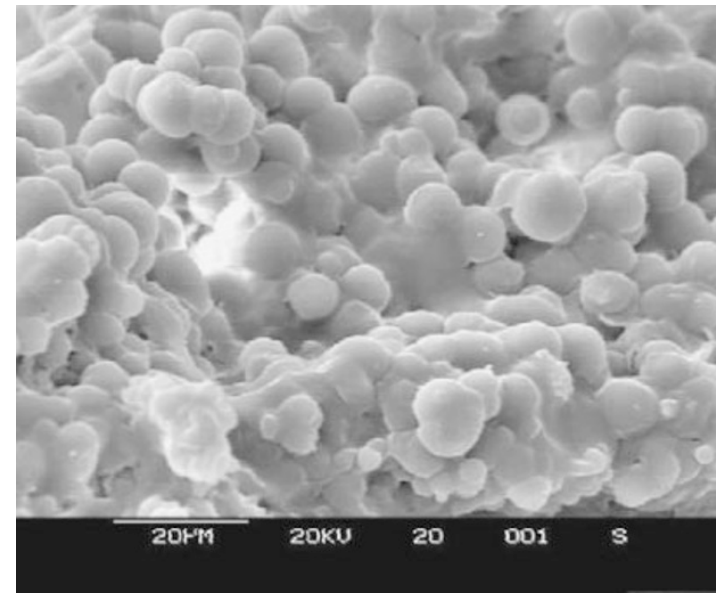

(c)

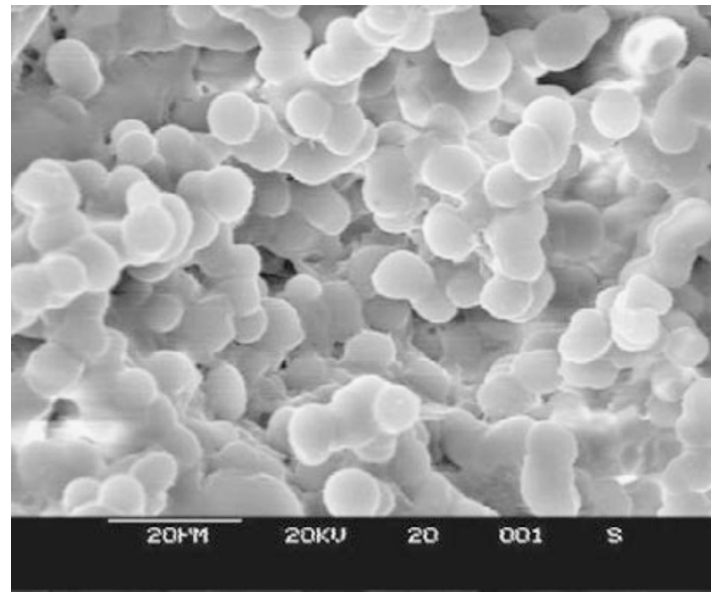

(d)

Figure 4. SEM micrographs of fractured membranes. The content of hard units (volume parts): (a) 10; (b) 18 ; (c) 23 ; (d) 28.

units increased, the individuality of the particles became more obvious. A further increase of the amount of hard units made the individuality of latexes even stronger, although some still were bound together. This binding was partially caused by coagulation, and partially by inter-particle crosslinking. During radical copolymerization, diffusion of the monomers, crosslinkers and even segments across the boundary of the droplets is expected to occur. As a result, inter-particle crosslinking is generated. Of course, in order to maintain the integrity of the membrane, some bonding among latexes is necessary.

Figure 5 show the morphology near the surface of the membrane. One can see that the latex-packing structure of the bulk was covered by a dense thin layer. This layer was generated via the aggregation of flexible segments and crosslinking.

Figure 6 shows the selectivity of the membrane exhibited a maximum as the content of the hard units increased. This was the result of two competing factors: size and polarity of the molecules.

A well-known mechanism of pervaporation can be described as solution-diffusion. ${ }^{21}$ The separation of the species can be identified as three consecutive steps: (i) solution of the liquid feed penetrant molecules at the upstream surface, (ii) diffusion through the membranes to the downstream side, and (iii) desorption of the penetrant in vapor form at the downstream surface of the membrane. The driving force of the permeation is the concentration gradient of the permeates across the membrane. The diffusivity of the penetrant in a swollen region is not very important unless the pervaporation rate is not high enough on the membrane of the permeation side. However, the actual pervaporation was not this simple. ${ }^{22}$ If the three steps above were the whole story of pervaporation, any alcoholphilic-hydrophobic materials, such as polybutylacrylate, could be perfectly used to separate ethanol from water. In fact, polybutylacrylate was proven to be a poor material for separating ethanol. ${ }^{18}$ There must be additional mechanisms and special attention should be paid to the diffusion process.

Besides the concentration gradient, the rate of diffusion was also controlled by the size and polarity of the 


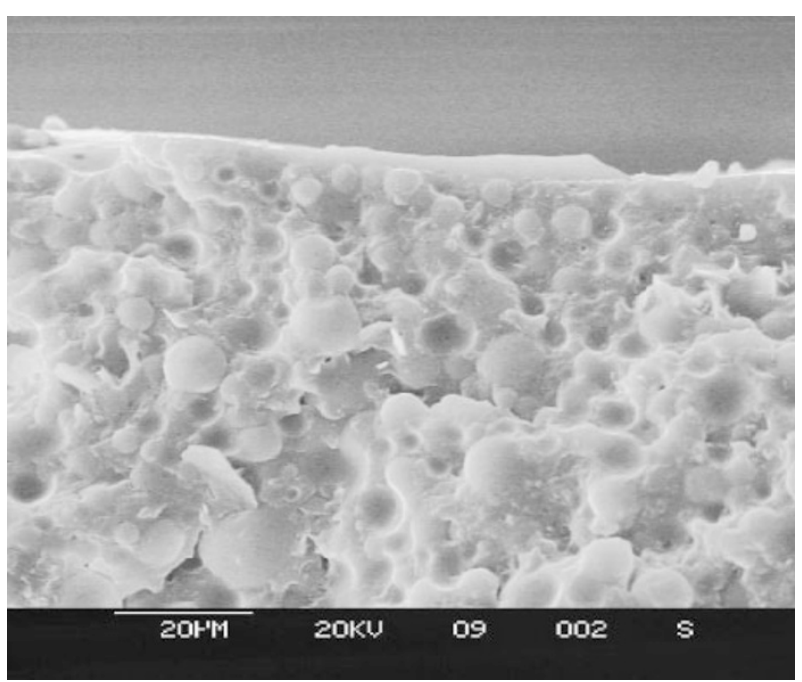

(a)

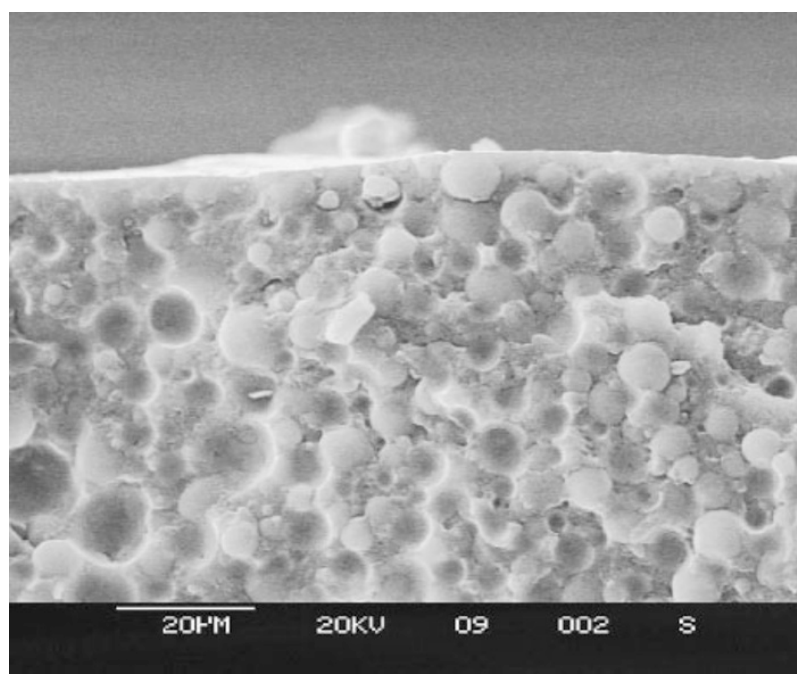

(b)

Figure 5. SEM micrographs of the membrane cross-section near the membrane surface. The content of hard units (volume parts): (a) 14, (b) 18 .

permeates. During the diffusion, a molecule was to move from one location to another that could accommodate it. The accommodation was determined mostly by both space room and polarity match. The moving to a too small or polarity un-matching location would be rejected. For this reason, different species possessed different rate in the diffusion, which constituted another mechanism of selectivity besides the solution mentioned above.

In the present case, the size of ethanol molecules is larger than those of water, however, its polarity is closer to the material (copolymer of polydimethylsiloxane and polystyrene). On the other hand, water molecules are unfavorable in polarity but smaller in size. In order to achieve an optimum selectivity for ethanol, the two factors should be compromised. In a dense membrane, the pathway of diffusion was sole-

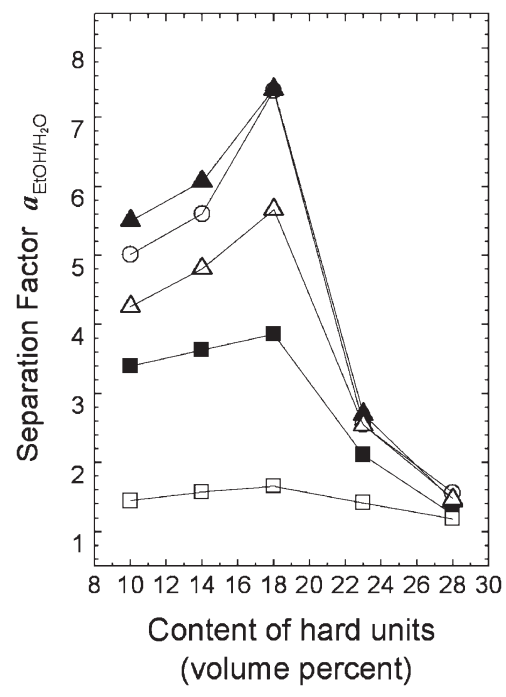

Figure 6. Dependence of the separation factor on the content of hard units and ethanol concentration in the feed. Volume percentage of ethanol in the feed: $\bigcirc 30 \%, \Delta 40 \%, \triangle 50 \%$, $60 \%, \square 80 \%$.

ly provided by the free volume among the segments. It was noticed that in the dense polymeric membrane the gap among the chains provides the pathway of the permeates. However, the average inter-chain distance among the amorphous flexible chains is $0.4-0.5 \mathrm{~nm}$ and the van der Waals radius of water and ethanol molecules are 0.26 and $0.52 \mathrm{~nm},{ }^{23}$ respectively. It would make more obstacles for ethanol than water. Via providing enlarged pathway, the diffusion of ethanol could be promoted. As seen in Figure 4, this was achieved through the increase of the individuality of the latexes and micro-channels surrounding the latexes were generated. The individuality of the latexes was controlled by the amount of hard units. When the loading of hard units was low, a major fraction of the latexes still bonded together, as shown in Figure 4a, the micro-channel structure was not well developed, and the selectivity of separation was low. When the hard units increased to a suitable amount, a maximum of selectivity was obtained. However, the enlargement of the pathway was accompanied by the decreased function of polarity. If the content of hard units was too high, selectivity was sharply decreased.

Figure 7 presents the effect of the content of hard units on the total permeation rate $J_{\mathrm{t}}$ for various compositions of the feed. One can see that $J_{\mathrm{t}}$ increased with increasing content of hard units. This increase occurs because the greater the amount of hard units, the less coagulation among cells occurs, and the larger the free volume. As already mentioned, this provided additional pathways for the permeates, which were available to both ethanol and water (see Figures 8 and 9).

However, the total permeation rate $J_{\mathrm{t}}$ was strongly 


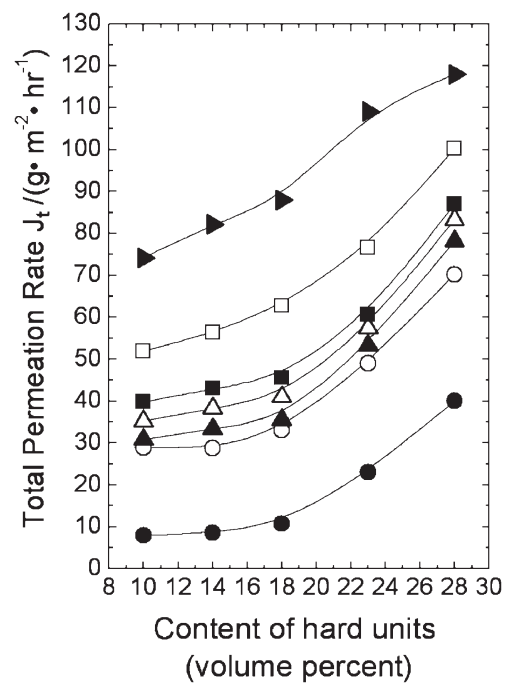

Figure 7. Dependence of the total permeation rate $J_{\mathrm{t}}$ on the content of hard units and ethanol concentration in the feed. Volume percentage of ethanol in the feed: - $0 \%, \bigcirc 30 \%, \Delta 40 \%$, $\triangle 50 \%, \square 60 \%, \square 80 \%, \triangleright 100 \%$.

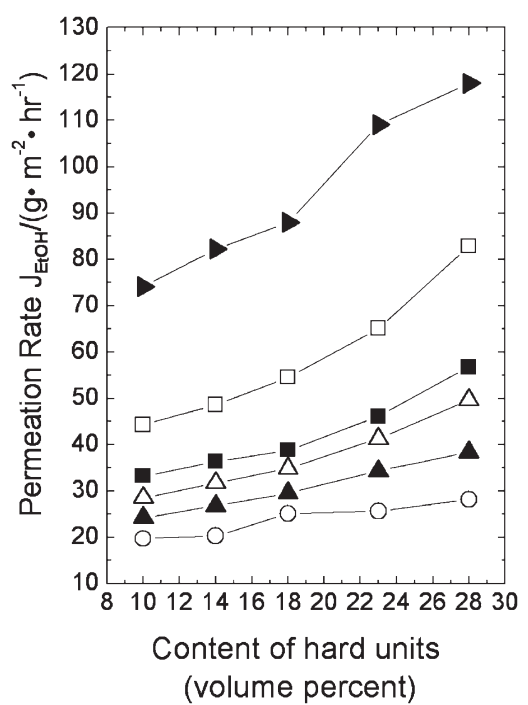

Figure 8. Dependence of ethanol permeation rate $J_{\mathrm{C}_{2} \mathrm{H}_{5} \mathrm{OH}}$ on the content of hard units and ethanol concentration in the feed. Volume percentage of ethanol in the feed: $\bigcirc 30 \%, \Delta 40 \%, \triangle$ $50 \%, \square 60 \%, \square 80 \%, \triangleright 100 \%$.

affected by the composition of the feed, because the higher the volume ratio of ethanol in the feed, the greater its absorption by the cells. This can be attributed to the hydrophobicity of the materials. Both polydimethylsiloxane and polystyrene are hydrophobic, and for this reason they prefer ethanol molecules to water.

It was generally observed that the increase in the flux was usually associated with a decrease in selectivity. ${ }^{11,12}$ However, comparing Figures 6 and 7, one can observe that, in certain ranges of composition, the flux and selectivity increase simultaneously.

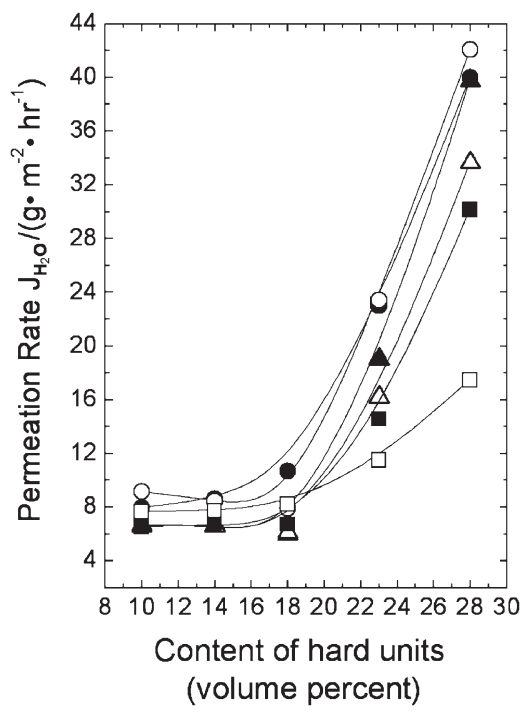

Figure 9. Dependence of water permeation rate $J_{\mathrm{H}_{2} \mathrm{O}}$ on the content of hard units and ethanol concentration in the feed. Volume percentage of ethanol in the feed: - $0 \%, \bigcirc 30 \%, \Delta 40 \%$, $\triangle 50 \%, \square 60 \%, \square 80 \%$.

\section{CONCLUSIONS}

A novel structured membrane composed of compacted latexes and coated with a dense layer was prepared via the concentrated emulsion polymerization. The latexes retained the shape and size of the precursor droplets of the concentrated emulsion. The coagulation of the latexes was controlled through the adjustment of the flexibility of the polymer chains. The gap among the latex region provided diffusion pathway in addition to those inside the dense latexes. The membrane showed good performance in separating ethanol from ethanol/water mixtures. As the individuality of the latexes increased, the permeation rate increased and the selectivity exhibited a maximum. In certain range of composition, the increase of flux was accompanied by an increase of selectivity.

Acknowledgment. It is a pleasure to acknowledge the financial support provided by the National Science Foundation of China Grant No. 50073003.

\section{REFERENCES}

1. B. Smitha, D. Suhanya, and S. Sridhar, J. Membr. Sci., 241, 1 (2004).

2. F. Lipnizki, R. W. Field, and P. K. Ten, J. Membr. Sci., 153, 183 (1999).

3. B. K. Datta, W. C. Ji, and S. K. Sikdar, Sep. Purif. Methods, 25, 131 (1997).

4. S. M. Zhang and E. Drioli, Sep. Sci. Technol., 30, 1 (1995).

5. G. F. Tusel and H. E. A. Bruschke, Desalination, 53, 327 (1985).

6. R. A. Shelden and E. V. Thompson, J. Membr. Sci., 9, 39 
(1984).

7. H. Strathmann, W. Gudernatsch, and B. Mattiasson, Ed., "Extractive Bioconversions," Marcel Dekker, New York, 1990.

8. Y. Mori and T. Inaba, Biotechnol Bioeng., 36, 849 (1990).

9. C. W. Cho and S. T. Hwang, J. Membr. Sci., 57, 21 (1991).

10. P. J. Hickey, F. P. Juricic, and C. S. Slater, Sep. Sci. Technol., 27, 843 (1992).

11. W. Zhang, X. J. Yu, and Q. A. Yuan, Biotechnol Tech., 9, 299 (1995).

12. Y. M. Lee, D. Bourgeois, and G. Belfort, J. Membr. Sci., 44, 161 (1989).

13. O. E. Hans, Karlsson, and T. Gun, J. Membr. Sci., 76, 121 (1993).

14. T. Shinsuke, Y. Hidedi, and T. Shoji, J. Membr. Sci., 75, 93 (1992).

15. I. Blume, J. G. Wijmans, and R. W. Baker, J. Membr. Sci.,
49, 253 (1990).

16. N. Yu, M. Shigehiro, and M. Kiyohide, J. Appl. Polym. Sci., 37, 1259 (1989).

17. M. Kakudo and N. Kasai, "X-ray diffraction by polymers," Elsevier Publishing Co., Tokyo, 127 (1972).

18. E. Ruckenstein and F. M. Sun, Ind. Eng. Chem. Res., 34, 3581 (1995).

19. F. M. Sun and E. Ruckenstein, J. Membr. Sci., 90, 275 (1994).

20. E. Ruckenstein, Adv. Polym. Sci., 127, 3 (1997).

21. A. Duggal and E. V. Thompson, J. Membr. Sci., 27, 13 (1986).

22. X. S. Feng and R. Y. M. Huang, Ind. Eng. Chem. Res., 36, 1048 (1997).

23. S. Mandal and V. G. Pangarkar, J. Membr. Sci, 201, 175 (2002). 